\title{
THE ASSOCIATION BETWEEN ADMISSION TO A TERTIARY CHILDREN'S HOSPITAL AND FUTURE UNPLANNED DENTAL PRESENTATION
}

\author{
Parmis Aminian', Estie Krugerl, Marc Tennant ${ }^{1}$ \\ 1. University of Western Australia, Perth WA, Australia
}

Correspondence: pa.aminian@gmail.com

\begin{abstract}
OBJECTIVE:

Dentistry should aim to prevent rather than focus on end-stage treatment which is more costly and less effective. This study investigated the association between unplanned dental presentations and any previous admissions at a tertiary hospital for children.
\end{abstract}

DESIGN:

A retrospective analysis of 351 unplanned dental presentations at PCH was performed.

SETTING:

A tertiary children's hospital, the Perth Children's Hospital (PCH).

\section{MAIN OUTCOME MEASURES:}

Reasons for unplanned presentations (infection, trauma, others) and the history of any previous admissions at PCH were analysed.

RESULTS:

Dental infection and trauma were the main reasons for the unplanned dental presentations. More than half of those who presented due to dental infection had at least once previous admission at PCH due to other reasons. Patients who presented with dental infection were more likely to have previous visits by community nurse or social worker, while those who presented due to trauma, were more likely to have had previous visits at orthopaedic or fracture wards of the same hospital.

\section{CONCLUSIONS:}

Community nurses and social workers can possibly play a role in informing patients about dental care options in the primary care sector.

\section{KEYWORDS}

Children, Tertiary Hospital, Dental 
INTRODUCTION

Paediatric dental health is an essential aspect of general child health and development. Dental caries is one of the most common chronic and costly diseases in children. [1] Although the proportion of children with dental caries has declined in Australia during the last 2 decades [2], hospital presentations for treatment of dental problems still have a considerable impact on Australian society. [3] Dental caries is a time-evolving condition, and chronicity is required for the condition to become significant enough to warrant hospital inpatient treatment. [4] Consequently inpatient treatment under general anaesthesia at a tertiary hospital can have a significant impact on the child (and family), society, and at a substantial cost to the health system that may have been prevented. Therefore, investigation of strategies for managing dental caries on a population level, and avoiding hospital presentation, is an important area of dental public health research.

The Perth Children's Hospital ( $\mathrm{PCH}$ ) is the only specialist paediatric hospital and trauma centre in Western Australia (WA). It is the major referral centre for children in WA. [5]

In Australia the public dental service provides limited dental care only for eligible parts of the population, and waiting times can be lengthy. [6] Private dental care is costly for patients, and not an easy option for all, especially for those who do not have private health insurance. Additionally, some individual patients might postpone simple dental treatment due to procedural anxiety. [7] The cumulation of potentially preventable dental diseases terminates into a complex dental disease which in turn results in delayed access to tertiary care, a larger reliance on public tertiary hospital care, and putting a preventable burden on the health system. When public health resources are limited, mitigation strategies are needed to manage disease burdens on society.

The objective of this retrospective study was to examine the histories of patients attending for emergency dental care at a specialist paediatric hospital to determine if there were previous admission at the same hospital, that may provide opportunities to intervene, and prevent the costly unplanned dental emergency presentations. The finding can facilitate innovative early intervention strategies and possibly reduce health system costs. Anecdotal evidence suggests that many child dental emergency patients have had recurrent admissions to a hospital prior to the dental emergency presentation. The null hypothesis of this study was that there is an association between acute unplanned dental presentation and having a history of previous admission at the hospital.

\section{METHODS}

Exemption from Ethics for this study was obtained from the Ethics Committee at the University of Western Australia (RA/4/20/5497) after the study was approved as a Quality Activity Study at the hospital (Number 33241).

De-identified retrospective patient data $(n=351)$ were obtained and analysed. The convenience sample data were collected from the first sequence of the day list of records of patients who had an unplanned presentation at the Perth Children's Hospital's dental department. In this study, unplanned dental presentation means patients who visited at PCH dental department (In-patient or Outpatient) without having an appointment including the patients who were referred from the emergency department of $\mathrm{PCH}$ or who had a referral from outside of the $\mathrm{PCH}$. Data were collected in 2017 and in 2019, but not in 2018 , as the hospital moved physical sites in that year, and any effects of the move on patient attendance was thus avoided. Data collected for this study included presentation date, the dental reasons for presentation, age, gender, Indigenous status, and a summary of previous admission at PCH (any previous admissions to the hospital, and to which wards/departments were the previous visits/admissions).

Data storage and statistical analyses were conducted by Microsoft Excel (Version XX, Microsoft Redmount USA). Significant differences were based on $P$ value $<0.05$. MedCalc software was used for comparison of proportions. [8]

Comparisons were also made between unplanned dental presentation due to dental infection (which could be preventable) and dental trauma (which is difficult to prevent).

\section{RESULTS}

The sample of unplanned dental presentations at $\mathrm{PCH}$ were included 159 (45.3\%) girls and 192 (54.7\%) boys. Out of 185 cases who presented because of dental infection there were not significant difference in gender, while 
among 148 dental trauma cases $64.9 \%(n=96)$ were boys and $35.1 \%(n=52)$ were girls $(P=0.0011<0.05)$. 18 cases were reported discomfort for reasons other than infection or trauma.

$190(54.1 \%)$ cases presented directly to the emergency department of the hospital and 161 (45.9\%) of them were referred by another health care services. The dental treatment of more than three-fifth (64.1\%) of patients had been accomplished under general anaesthesia. $11.1 \%$ of them had Indigenous status and almost $80 \%$ were from Perth metropolitan area.

The age of the patients ranged from 10 months to 19 years; with the average aged 5.8 years. The most frequent presentation age was 4 years old.

Of 351 cases, almost half $(47.6 \%)$ of them had at least one previous admission to $\mathrm{PCH}$ (Table 1). Previous admission means visited as an In-patient to any departments of the hospital, not only dental. For analysing purposes, two categories were created: those who had a previous admission ( $n=167)$, and those with no previous admission $(n=184)$. There were no significant differences in reason for unplanned dental presentation between the two groups (previous admitted and no previous admitted) (Table 1).

The main reasons for unplanned presentation were dental infection and dental trauma. Of all the presentations, $52.7 \%$ had a problem resulting from dental infection, $42.2 \%$ experienced dental trauma, and $5.1 \%$ presented for other reasons.

The study found that $50.8 \%$ of patients with dental infection had at least one previous admission to $\mathrm{PCH}$ (for other medical issues), and $43.9 \%$ of patients with dental trauma had a previous admission to PCH (Table 1).

\section{TABLE1: PREVIOUS ADMISSION AND REASONS FOR UNPLANNED DENTAL PRESENTATIONS}

\begin{tabular}{|l|l|l|}
\hline $\begin{array}{l}\text { UNPLANNED DENTAL } \\
\text { PRESENTATION }\end{array}$ & $\begin{array}{l}\text { NO PREVIOUS } \\
\text { ADMISSION }\end{array}$ & $\begin{array}{l}\text { AT LEAST ONCE PREVIOUS } \\
\text { ADMISSION }\end{array}$ \\
\hline Infection Reasons (185) & $49.2 \%(91)$ & $50.8 \%(94)$ \\
\hline Trauma Reasons (148) & $56.1 \%(83)$ & $43.9 \%(65)$ \\
\hline Other Reasons (18) & $55.6 \%(10)$ & $44.4 \%(8)$ \\
\hline Total (351) & $52.4 \%(184)$ & $47.6 \%(167)$ \\
\hline
\end{tabular}

Children who had previous medical admission to $\mathrm{PCH}$, attended at various wards of the hospital before the unplanned dental presentation (Table 2). Some patients attended several (different) wards previously. The most common "wards" of the hospital previously admitted by dental patients were Ear, Nose and Throat (ENT \& Audiology), General Medicine (General \& Paediatric Medicine), Surgeries (General \& Paediatric \& Plastic Surgeries), Orthopaedic (Plastic, Orthopaedic, Fracture), Community Nurse and Social Work.
In total the proportion of dental patients who had previously been admitted to ENT and Surgery were slightly more than other parts of the hospital (Table 2).

In this study, the patients who had visited community nurses or social workers were more likely to have unplanned dental presentation because of dental infections. Patients who had a previous admission to the orthopaedics or fracture ward at $\mathrm{PCH}$, were more likely to present at the dental department as a result of dental trauma (rather than dental infection) (Table 2, Figure 1). 
TABLE 2: PREVIOUS WARDS VISITED AND REASONS FOR UNPLANNED DENTAL PRESENTATIONS

\begin{tabular}{|c|c|c|c|c|}
\hline MEDICAL WARDS & $\begin{array}{l}\text { ORAL } \\
\text { INFECTION } \\
185\end{array}$ & $\begin{array}{l}\text { ORAL } \\
\text { TRAUMA } \\
148\end{array}$ & $\begin{array}{l}\text { OTHER ORAL } \\
\text { PROBLEMS } \\
18\end{array}$ & $\begin{array}{l}\text { TOTAL } \\
\text { NUMBER } \\
351\end{array}$ \\
\hline ENT & $28(15.1 \%)$ & $18(12.2 \%)$ & $2(11.1 \%)$ & $48(13.7 \%)$ \\
\hline General Medicine & $21(11.3 \%)$ & $21(14.2 \%)$ & $5(27.8 \%)$ & $47(13.4 \%)$ \\
\hline Surgeries & $31(16.7 \%)$ & $22(14.9 \%)$ & $1(5.6 \%)$ & $54(15.4 \%)$ \\
\hline Orthopaedic & $16(8.6 \%)$ & $29(19.6 \%)$ & $1(5.6 \%)$ & $46(13.1 \%)$ \\
\hline Community Nurse \& Social work & $30(16.2 \%)$ & $8(5.4 \%)$ & $2(11.1 \%)$ & $40(11.4 \%)$ \\
\hline Physiotherapy & 5 & 3 & 0 & 8 \\
\hline Respiratory & 8 & 2 & 1 & 11 \\
\hline Ophthalmology & 8 & 6 & 1 & 15 \\
\hline Cardiology & 3 & 4 & 1 & 8 \\
\hline Renal & 4 & 3 & 0 & 7 \\
\hline Speech therapy & 5 & 2 & 0 & 7 \\
\hline Occupational therapy & 5 & 3 & 0 & 8 \\
\hline Others & 45 & 30 & 12 & 87 \\
\hline
\end{tabular}

FIGURE 1: PROPORTION OF UNPLANNED DENTAL PATIENTS DUE TO INFECTION VERSUS TRAUMA BY PREVIOUS WARD ADMISSIONS.

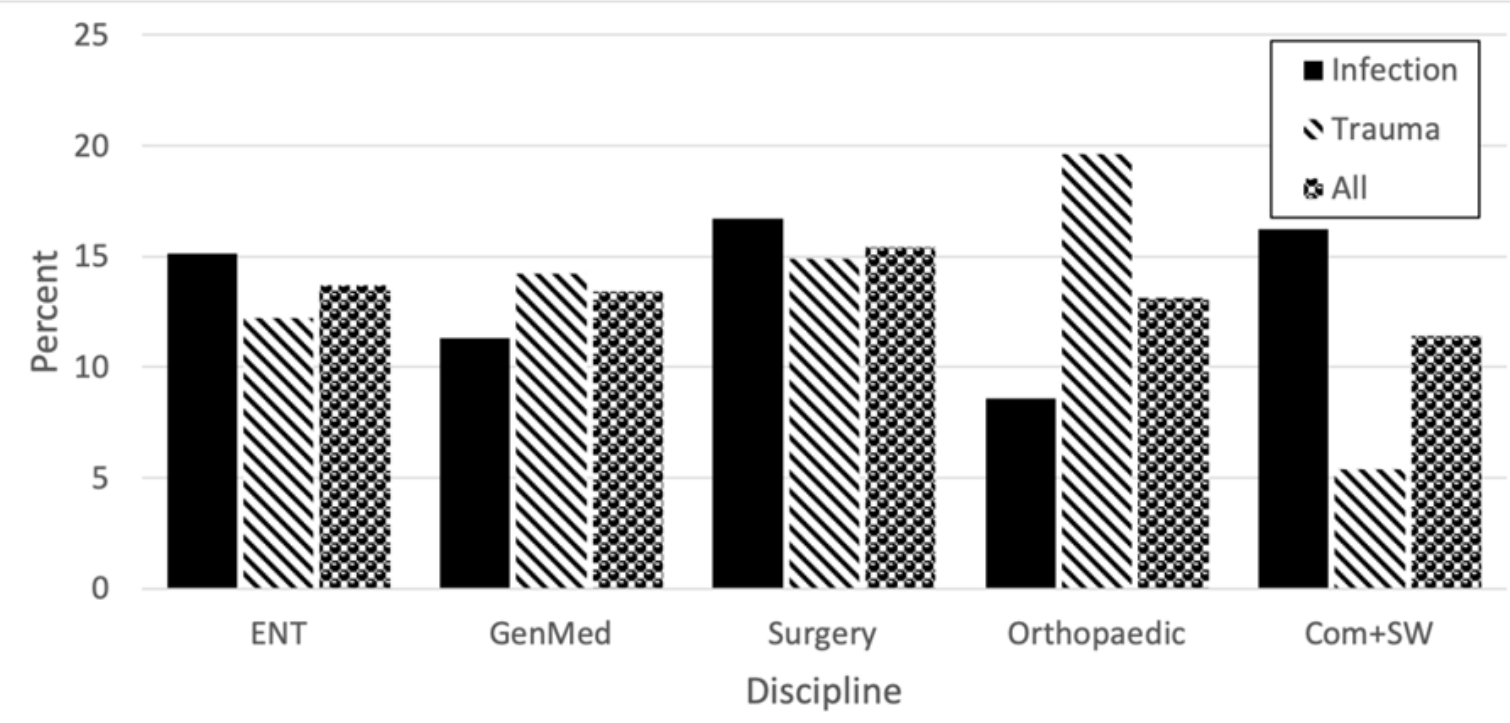


There was a significant statistical difference in presentation due to dental infection compared to dental trauma in patients who had previous visits to the Orthopaedics wards, or with Community nurses and social workers ( $P$ value $<0.05$ ) (Table 3).
The proportions between those who presented with infection versus trauma is different between the groups of patients who have had previous admission to ENT, general medicine and surgery wards at $\mathrm{PCH}$, but they were not statistically significant (P value> 0.05) (Table 3).

\section{TABLE 3: DIFFERENCES BETWEEN TWO GROUPS (PRESENTATIONS FOR INFECTION AND PRESENTATION FOR TRAUMA), BY PREVIOUS WARDS VISITED}

\begin{tabular}{|l|l|l|l|l|l|}
\hline $\begin{array}{l}\text { MOST COMMON PCH } \\
\text { WARDS HAD BEEN } \\
\text { VISITED BY UNPLANNED } \\
\text { DENTAL PATIENTS }\end{array}$ & ENT & $\begin{array}{l}\text { GENERAL } \\
\text { MEDICINE }\end{array}$ & SURGERY & ORTHOPAEDIC & $\begin{array}{l}\text { COMMUNITY } \\
\text { NURSE \& } \\
\text { SOCIAL } \\
\text { WORK }\end{array}$ \\
\hline Infection(185) & $28(15.1 \%)$ & $21(11.3 \%)$ & $31(16.7 \%)$ & $16(8.6 \%)$ & $30(16.2 \%)$ \\
\hline Trauma(148) & $18(12.2 \%)$ & $21(14.2 \%)$ & $22(14.9 \%)$ & $29(19.6 \%)$ & $8(5.4 \%)$ \\
\hline P* & 0.4466 & 0.4286 & 0.6558 & 0.0036 & 0.0021 \\
\hline
\end{tabular}

$\mathrm{P}<0.05$ deemed significant, Chi-square tests between categories.

\section{DISCUSSION}

In this study, dental Infections and trauma were the most common reasons for unplanned dental presentations at the tertiary children's hospital. A study from the US also showed that the main reasons for dental attendance at the emergency department of a hospital were trauma and dental caries (51\% trauma, 40\% caries, $9 \%$ other reasons). [9]

There were no previous studies in the literature investigating if child emergency dental patients had any previous admission to a tertiary children's hospital.

Prevention of acute dental infection in children would not only improve the general and dental health of children, but at the same time also reduce the burden on tertiary hospitals. Dental trauma due to accidents is difficult to prevent, but dental infection is usually the result of untreated dental caries, and takes a while to progress to a point where hospital treatment is unavoidable. Strategies to identify children at high risk for dental caries, and subsequent prevention in the primary sector, might prevent later unplanned dental presentation and hospitalisation for dental treatment. The results of this study have shown near to half of the unplanned dental patients (47.6\%) have had a previous admission to the Perth Children's Hospital for different issues. About half of those who presented with dental infection (50.8\%) had at least one previous admission to the hospital. Therefore, about half of the high risk group had already had some contact with the health system, and available to receive possible intervention strategies for prevention of dental infection.

The results have shown that the patients who had been visited by community nurses or social workers are more likely to present for an unplanned dental presentation because of dental infection (Table 3, $\mathrm{P}<0.05$ ). Community nurses mainly monitor growth indices, developmental milestones, give advice on nutrition, mental health for mothers and children. Social workers look after family well-being, domestic violence, housing, transportation, disability resources, NDIS registration and paperwork. They also can advocate for the patients and their families to get funds and have their registration, pension cards, or schooling issues. Consequently, it can be presumed those underprivileged children or probably patients with sociocommunity problems, are more likely to visit community nurses or social workers. The strong association between socio-economic disadvantage and poor oral health among Australian children has been well-established. [10] Therefore, community nurses and social workers can be helpful as a point of contact and refer to primary dental services.

In addition, this study has shown that patients who had a previous admission to orthopaedic or fracture wards at $\mathrm{PCH}$, were more likely to present with dental trauma or a dental injury. It seems that some children might be more accident prone. Although the aetiology of dental trauma 
cases was not investigated in this study, previous studies indicate that dental trauma in children is most likely caused by falls, sport, traffic accidents, violence, inappropriate use of teeth or biting a hard item, and others depend on population type, age, culture, region in the world and environment. $[11,12,13]$ It is possible that certain sports or ages are more at risk of dental trauma. Based on our findings it might be suggested that children admitted at orthopaedic or fracture wards at hospital, be provided with advice on the use of helmets or sport mouth guards when they are playing sports or riding. In this study, there was a significant difference between boys and girls for a dental trauma accident $(p<0.05)$. Other studies also have reported that boys experienced dental injures more often than girls. $[9,11,13]$

Many children who had unplanned dental presentations at $\mathrm{PCH}$ have had previous admission to this tertiary hospital because of surgery, ENT or general medicine problems so they visited a paediatrician. Hence, paediatricians potentially could be helpful for prevention of dental disease. The analysis of national survey data in the U.S revealed that more than $90 \%$ of paediatricians agreed about their valuable role on the promotion of oral health and counselling families on the prevention of dental problems, however they reported lack of previous training in dental health issues during their academic education. [14] Increasing the information of paediatricians about preventive dental care could be another recommendation in order to reduce unplanned dental presentation.

Previous works found a connection between middle ear or respiratory tract infection in early childhood and increasing chances of severe dental caries in the future. [15,16] Some studies have also shown that frequent infectious diseases in early childhood can be associated with enamel hypoplasia, leading to increased susceptibility for dental caries. [17] In this study, although ENT was one of the most common wards in which the unplanned dental patients had a past history of admission, there was no significant association between unplanned dental presentation and previous ENT admission to the same hospital. Nelson et al. (2005) also reported that there is no relationship between ear infections and dental caries in preschool-aged children. [19]

A New Zealand study showed that Early Childhood Caries (ECC) among preschool children was not associated with admission for other medical conditions but it was closely related to injury admissions. This association could have other contributory factors, such as social factors, including underprivileged children from poor residential environments, large families, and inexperienced young mothers. [20] In addition, the study in New Zealand found that the most deprived children had higher prevalence of early childhood caries. [20] This study however was difficult to compare with our findings, due to a different study population (age), different health system and different methodology used.

One of the limitation of this study was to obtain a larger sample size, and lack of some available data due to ethical and privacy concerns. Future study with a bigger sample size in which looking for other different underlying variables could be useful.

\section{CONCLUSION}

Dental infections and trauma lead to a significant burden of unplanned dental presentations at the tertiary children's hospital in Western Australia. As dental infections is a preventable condition, preventive and timely general dental care could avoid unplanned hospital presentations. Dental caries could have been managed by general dentists, if the patients are treated in the early stage of the disease. Health workers at hospitals, such as paediatricians, social workers and community nurses can be helpful in increasing awareness about dental care and/or referral for dental treatment, as many children are likely to have contact with these services prior to dental problems developing. Effective effort is necessary to develop dental care policies and programmes targeted to high-risk children.

\section{This research did not receive any specific funding. The authors declare no conflicts of interest.}

\section{References}

1. Mouradian WE, Wehr E, Crall JJ. Disparities in children's oral health and access to dental care. JAMA. 2000;284(20):2625-2631. doi:10.1001/jama.284.20.2625

2. Spencer AJ, Davies M, Slade G, Brennan D. Caries prevalence in Australasia. Int Dent J. 1994;44(4 Suppl 1):415-423.

3. Alsharif A, Kruger E, Tennant M. Future projections of child oral-related hospital admission rates in Western 
Australia. Aust J Prim Health. 2016;22(6):491-496. doi:10.1071/PY15132

4. Selwitz RH, Ismail Al, Pitts NB. Dental caries. Lancet. 2007;369(9555):51-59. doi:10.1016/S01406736(07)60031-2

5. Child and Adolescent Health Service, Government of Western Australia. History and designe. PCH. Available: https://pch.health.wa.gov.au/About-us/History

6. Australian Government, Department of Health. Guide to the Child Dental Benefits Schedule. Australian Government 2014 Available:

http://www.health.gov.au/internet/main/publishing.ns f/Content/childdental (updated 01 January 2018)

7. Verma S, Chambers I. Dental emergencies presenting to a general hospital emergency department in Hobart, Australia. Aust Dent J. 2014;59(3):329-333. doi:10.1111/adj.12202

8. Schoonjans F. MedCalc easy-to-use statistical software. MedCalc 2017. Available:

<https://www.medcalc.org/calc/comparison_of_prop ortions.php> (Verified 7 March 2020)

9. Rowley ST, Sheller B, Williams BJ, Mancl L. Utilization of a hospital for treatment of pediatric dental emergencies. Pediatr Dent. 2006;28(1):10-17.

10. Peres MA, JU X, Spencer AJ. Social gradients in child oral health. In: Do LG and Spencer AJ, editors. Oral health of Australian children: The National Child Oral Health Study 2012-14. Adelaide:University of Adelaide Press; 2016. p. 237-263.

11. Fleming P, Gregg TA, Saunders ID. Analysis of an emergency dental service provided at a children's hospital. Int J Paediatr Dent. 1991;1 (1):25-30. doi:10.1111/j.1365-263x.1991.tb00317.x

12. Glendor U. Aetiology and risk factors related to traumatic dental injuries--a review of the literature. Dent Traumatol. 2009;25(1):19-31. doi:10.1111/j.16009657.2008.00694.x

13. Nalliah RP, Rampa S, Lee MK, Allareddy V, Allareddy $\checkmark$. Epidemiology and Outcomes of Hospital-based Emergency Department Visits with Tooth Fractures. Pediatr Dent. 2015;37(4):348-354.

14. Lewis CW, Grossman DC, Domoto PK, Deyo RA. The role of the pediatrician in the oral health of children: $A$ national survey. Pediatrics. 2000;106(6):E84. doi:10.1542/peds.106.6.e84

15. Alaki SM, Burt BA, Garetz SL. Middle Ear and Respiratory Infections in Early Childhood and Their
Association With Early Childhood Caries. Pediatr Dent. 2008;30:105-110.

16. Kashyap N, Katlam T, Avinash A, Kumar B, Kulshrestha $R$, Das $P$. Middle ear infection in children and its association with dental caries. Med Pharm Rep. 2019;92(3):271-276. doi:10.15386/cjmed-1043

17. Sweeney EA, Cabrera J, Urrutia J, Mata L. Factors associated with linear hypoplasia of human deciduous incisors. J Dent Res. 1969;48(6):1275-1279. doi:10.1177/00220345690480063201

18. Tapias-Ledesma MA, Jiménez R, Lamas F, González A, Carrasco P, Gíl de Miguel A. Factors associated with first molar dental enamel defects: a multivariate epidemiological approach. J Dent Child (Chic). 2003;70(3):215-220.

19. Nelson S, Nechvatal N, Weber J, Canion S. Dental caries and ear infections in preschool-aged children. Oral Health Prev Dent. 2005;3(3):165-171.

20. Aung YM, Tin Tin S, Jelleyman T, Ameratunga S. Dental caries and previous hospitalisations among preschool children: findings from a population-based study in New Zealand. N Z Med J. 2019;132(1493):44-53. Published 2019 Apr 12. 